\title{
Genetic and Epigenetic Inactivation of TNFRSF10C in Human Prostate Cancer
}

\author{
Yu Cheng ${ }^{1,2}$, Jin Woo Kim ${ }^{1,2,3}$, Wennuan Liu ${ }^{1,2}$, Thomas A Dunn ${ }^{4}$, Jun Luo ${ }^{4}$, Matthew J \\ Loza $^{2}$, Seong-Tae $\mathrm{Kim}^{1,2}$, Siqun Lilly Zheng ${ }^{1,2}$, Jianfeng $\mathrm{Xu}^{1,2}$, William B. Isaacs ${ }^{4, \dagger}$, and \\ Bao-Li Chang \\ ${ }^{1}$ Center for Cancer Genomics, Wake Forest University School of Medicine, Winston-Salem, NC \\ ${ }^{2}$ Center for Human Genomics, Wake Forest University School of Medicine, Winston-Salem, NC \\ ${ }^{3}$ Department of Cancer Biology, Wake Forest University School of Medicine, Winston-Salem, NC \\ ${ }^{4}$ Department of Urology, Johns Hopkins University School of Medicine, Baltimore, MD
}

\begin{abstract}
BACKGROUND-TNFRSF10C, is located on 8p21.3, one of the most frequently deleted loci in the genome of prostate cancer (PCa). Hypermethylation of TNFRSF10C promoter CpG island (CGI) had been reported in many tumors including PCa. However, the interplay between somatic deletion and promoter hypermethylation of TNFRSF10C on PCa development has not been investigated.
\end{abstract}

METHODS-Methylation status of promoter CGI and deletion status of the TNFRSF10C locus was investigated by bisulfite sequencing and Affymetrix SNP array, respectively in 59 pairs of PCa tumor and matched normal samples with $3 \mathrm{PCa}$ cell lines. TNFRSF $10 \mathrm{C}$ gene expression changes in relation to cancer-associated genetic/epigenetic changes in clinical specimens, and change of TNFRSF10C expression before and after 5-aza-2'-deoxycytidine treatment in the PC3 PCa cell line were assessed by real-time RT-PCR.

RESULTS-We found that TNFRSF10C promoter CGI was differentially methylated in 46 of 59 primary cancers $(78.0 \%)$. Hemizygous deletion at TNFRSF10C was found in 44 of the 59 prostate tumors (74.5\%). Interestingly, in $94.9 \%$ of the tumors (56 out of 59), TNFRSF10C was either hemizygously deleted or its promoter CGI hypermethylated. Deletion and/or methylation of the TNFRSF10C gene was correlated with decreased mRNA expression of the gene in clinical specimens. Demethylation of the TNFRSF10C promoter CGI was accompanied by transcriptional re-activation of TNFRSF10C in the prostate cancer cell line PC3.

CONCLUSION-We found a notably high frequency of promoter CGI methylation and deletion of TNFRSF10C in PCa tissues. Our results indicated that inactivation of TNFRSF10C by chromosomal deletion and promoter methylation may play an important role in PCa development.

\section{Keywords}

promoter methylation; $\mathrm{CpG}$ islands; somatic copy number alterations

$\dagger$ Address for correspondence: Dr. Bao-Li Chang, Ph.D., Center for Human Genomics, Medical Center Blvd., Winston-Salem, NC 27157, Phone: (336)713-7148, Fax: (336)713-7566, bchang@wfubmc.edu, or Dr. William B. Isaacs, Ph.D., Marburg 115, Johns Hopkins Hospital, 600 N. Wolfe Street, Baltimore, MD 21287, Phone: (410)955-2518, Fax: (410)955-0833, wisaacs@jhmi.edu. 


\section{INTRODUCTION}

The tumorigenesis of prostate cancer (PCa) is a multi-step process involving various factors, including dietary factors, lifestyle-related factors, androgen and the accumulation of genetic and epigenetic alterations [1]. Because of its exceptionally high incidence in the U.S., discovering the molecular basis of PCa is a priority of our research. The short arm of chromosome 8 was the most commonly deleted region in prostate cancer DNA [2]. Sun et al. found seven cytogenetic bands (8p23.1-8p21.1) had a higher frequency of deletion. Chang and Liu et al. further found two important consensus prostate cancer-susceptibility regions $8 \mathrm{p} 21.3$ (20.6-23.7 Mb) and 8p23.1 (9.8-11.2 Mb) by combined somatic deletion and germline linkage analyses [3], indicating these two regions may contain candidate tumor suppressor genes (TSGs) of PCa.

Generally, the functions of TSGs are disrupted by various genetic and epigenetic events that result in complete or incomplete loss of suppressor function and contribute to carcinogenesis. Genetic mutations including point mutation, deletions and translocation disrupt TSGs functioning, whereas epigenetic changes like hypermethylation of $\mathrm{CpG}$ islands in promoter can also inactivate TSGs. Recently, several studies have showed biallelic inactivation of TSGs by different combinations of genetic and epigenetic changes in several cancers, such as biallelic inactivation of $V H L$ through loss of heterozygosity $(\mathrm{LOH})$, somatic mutation, and promoter methylation in cRCC [4], similar inactivation of $D L C l$ and $L T F$ in nasopharyngeal carcinoma, $B R C A l$ in breast cancer, and $R I Z 1$ and $V L D L R$ in gastric cancer [5-9]. Therefore simultaneous examination of genetic and epigenetic alterations would increase the likelihood of detecting genes that are important in PCa development and progression.

TNFRSF10C (tumor necrosis factor receptor superfamily, member 10c), one of several TRAIL (TNF-related apoptosis inducing ligand-like) decoy receptors, is a glycosylphosphatidylinositol (GPI)-linked membrane molecule that lacks a cytoplasmic region. TNFRSF10C is located on 8p21.3 (23.01 23.03 Mb), which is within one of the two important consensus prostate cancer-susceptibility regions at $8 p$ [3], and is one of the most frequently deleted loci in the genome of various cancers like colon [10], lung [11], prostate [12], breast [13], bladder [14], and head-and-neck cancer [15]. Hypermethylation of TNFRSF10C promoter CGI had been reported in neuroblastoma (21\%) [16], primary breast cancer $(33 \%)$, primary lung cancer $(16 \%)$, malignant mesothellomas $(63 \%)$, prostate cancer (50\%) [17], ependymoma (50\%) and choroid plexus papillomas (50\%) [18]. Additionally, in a recent study by Hornstein et al, a significantly reduced expression of TNFRSF10C in $\mathrm{M}_{0}$ stage was found in prostate carcinomas compared to benign prostate tissue, suggesting TNFRSF10C as a new prostate cancer TSG [19].

In present study we examined the frequency of TNFRSF10C promoter hypermethylation in 59 pairs of prostate cancer and matched normal samples using bisulfite sequencing with a subcloning method. The status of somatic copy number alteration at the TNFRSF10C locus was analyzed for the same set of samples using our previous data. We then evaluated whether there is correlation between TNFRSF10C promoter CGI hypermethylation and deletion with clinicopathologic features such as Gleason score. We have also assessed TNFRSF10C gene expression changes in relation to cancer-associated genetic/epigenetic changes in clinical specimens, as well as change of TNFRSF10C expression before and after 5-aza-2'deoxycytidine treatment in the PC3 PCa cell line. 


\section{MATERIALS AND METHODS}

\section{Study Subjects}

All subjects in this study were prostate cancer patients undergoing radical prostatectomy for treatment of clinically localized disease at the Johns Hopkins Hospital. We selected 59 subjects from whom genomic DNA of sufficient amount $(>5 \mathrm{~g})$ and purity $(>70 \%$ cancer cells for cancer specimens, no detectable cancer cells for normal samples) could be obtained by macrodissection of matched nonmalignant (hereafter referred to as "normal") and cancer containing areas of prostate tissue as determined by histological evaluation of H\&E stained frozen sections of snap-frozen radical prostatectomy specimens. Genomic DNA was isolated from trimmed frozen tissues as described previously [20].

\section{Bisulfite Modification}

Genomic DNA from all prostate samples ( $250 \mathrm{ng}$ ) was subjected to sodium bisulfite modification using EZ DNA methylation-Gold kit following the manufacturer's protocol (Zymo Research, Orange, CA). The manufacturer's recommended alternative reaction conditions were chosen for the modification reaction $\left(98^{\circ} \mathrm{C}\right.$ for $10 \mathrm{~min}, 53^{\circ} \mathrm{C}$ for $30 \mathrm{~min}$, followed by 8 cycles at $53{ }^{\circ} \mathrm{C}$ for $6 \mathrm{~min}$ and $37^{\circ} \mathrm{C}$ for $30 \mathrm{~min}$ ).

\section{Bisulfite DNA Sequencing Analysis}

Methylation status was analyzed by bisulfite sequencing. Bisulfite sequencing primers were designed by Methyl Primer Express software (Applied Biosystems, Foster City, CA) to amplify bisulfite modified DNA. The TNFRSF10C bisulfite sequencing primers (forward 5'GGAAAGAGTTAGTTTTTGTTYG -3', reverse 5'-CTATCCCCAAAATTCCCT-3') can amplify a 307 base-pair (bp) product including $13 \mathrm{CpG}$ dinucleotides. The PCR was performed in a total volume of $12.5 \mu$ l containing $10 \times$ buffer, $0.1 \mathrm{mM}$ dNTP, and $0.04 \mathrm{U}$ HotStarTaq ${ }^{\mathrm{TM}}$ Polymerase (Qiagen, Valencia, CA), and $0.12 \mu \mathrm{M}$ of each primer. The PCR was carried out in a thermocycler with the following conditions: one cycle of $95^{\circ} \mathrm{C}$ for 15 minutes followed by 45 cycles of $94{ }^{\circ} \mathrm{C}$ for 30 seconds, $56{ }^{\circ} \mathrm{C}$ for 30 seconds, and $72{ }^{\circ} \mathrm{C}$ for 60 seconds, ending with one cycle of $72^{\circ} \mathrm{C}$ for 10 minutes. Amplified PCR products were separated by electrophoresis of $1.5 \%$ agarose gels and visualized by ethidium bromide staining, then $0.5 \sim 1$ $\mu 1$ PCR products were subcloned using the TOPO TA cloning kit (Invitrogen, Carlsbad, CA). After transformation using Escherichia coli, we randomly selected 10-20 individual E. coli colonies for each sample assessed. Plasmid DNA was directly amplified without bacterial culture (Templiphi amplification kit; GE healthcare). 10 to 20 plasmids were then sequenced using BigDye Terminator v1.1 Cycle Sequencing Kits (Applied Biosystems) with M13 reverse primers. The sequence data were compared with the UCSC genome Ref sequence in order to assess the methylation status of each $\mathrm{CpG}$ site.

\section{Cell Culture and Drug Treatment}

LNCaP, PC3, and DU145 were used. LNCaP and DU145 were maintained in RPMI-1640 supplemented with $5 \%$ fetal bovine serum (FBS) (Invitorogen) and $1 \%$ penicillin/streptomycin (Invitrogen), while PC3 was cultured in advanced DMEM with 1\% Glatamax, $5 \%$ FBS and $1 \%$ penicillin/streptomycin. All these cell lines were kept at $37^{\circ} \mathrm{C}$ and $5 \% \mathrm{CO}_{2}$ in a humidified incubator.

PC3 prostate cancer cells were treated with 5-aza-2'-deoxycytidine (Sigma-Aldrich Co, St. Louis, MO) dissolved in dimethyl sulfoxide at a final concentration of $2 \mu \mathrm{M}$ for four days. The same volume of DMSO was added as a control. Cells were allowed to grow for $96 \mathrm{~h}$, with changing of chemical-containing medium every $24 \mathrm{~h}$. Three independent experiments were performed. 


\section{Isolation of Genomic DNA and mRNA From Treated Cells}

$1 \mathrm{ml}$ of Trizol reagent (Invitrogen) was added to a PBS washed cell culture dish. Following the manufacturer's protocol, RNA was isolated from the aqueous phase of a Trizol-Chloroform mixture. Isolated RNA was treated with DNase I to remove any contaminated genomic DNA. DNase-treated RNA was re-purified using a Micro-to-Midi total RNA purification system (Invitrogen).

Genomic DNA of cultured cells was isolated from the inter-organic phase of a TrizolChloroform mixture. $0.5 \mathrm{ml}$ of Back Extraction Buffer (4 M guanidine thiocyanate, $50 \mathrm{mM}$ sodium citrate and $1 \mathrm{M}$ Tris $\mathrm{pH}$ 8.0) was added to the inter-organic phase of a TrizolChloroform mixture. After vigorously mixing by inversion, phase separation was performed by centrifugation at $12000 \times \mathrm{g}$ for $30 \mathrm{~min}$. DNA was precipitated from the upper aqueous phase by adding isopropanol. Isolated DNA was further purified using Gentra Puregene reagent (Qiagen) with proteinase $\mathrm{K}$ treatment, because protein contamination is one of the main sources of false positive bisulfite sequencing [21]. We followed the manufacturer's protocol.

\section{Real-time Reverse-transcriptase (RT) PCR}

Real-time RT-PCR was performed using both clinical specimens and cell lines. For clinical specimens, samples were processed and total RNA isolated as described previously [22]. Briefly, $0.125 \%$ of the cDNA product from 500ng of total RNA was used in the iQ SYBR Green Supermix assays (Bio-Rad, Hercules, CA). Recognizing the variable expression of most of the commonly used control genes in clinical specimens, previously published expression microarray data was analyzed and SF3A3 was identified and established as an ideal reference gene for normalization due to its stable expression levels among various prostate specimens including metastatic prostate cancer, primary prostate cancer, and normal prostate samples [23]. Only primers pairs with validated amplification specificity were used. Primer pairs used for TNFRSF10C: 5'-CACCAACGCTTCCAACAATGAACC-3' (forward primer). 5'-

TCCGGAAGGTGCCTTCTTTACACT-3' (reverse primer). Primer pairs used for SF3A3: 5' TACGAAAGGAGGAGCTCAATGCAA-3' (forward primer), 5' -

AGATCTCATTTGGGTGCTTCCGGT-3' (reverse primer). Following validation of equal efficiencies of amplification for both target genes and control genes, the average threshold cycle $(\mathrm{Ct})$ numbers from the triplicates for each sample were used for comparative threshold analysis as described [24].

For real-time RT-PCR in cell lines, $0.6 \mu \mathrm{g}$ of mRNA was reverse transcribed into cDNA with random hexamers using the ThermoScript RT-PCR system (Invitrogen) according to the manufacturer's protocol. A published TNFRSF10C primer was used [25], and GAPDH was chosen as an endogenous housekeeping gene (RealTimePrimers.com, Elkins Park, PA). The primer sequence information for TNFRSF10C and GAPDH were as follows: 5'-

CCCTAAAGTTCGTCGTCGTCAT-3' (TNFRSF10C forward), 5'-

GGGCAGTGGTGGCAGAGTA-3' (TNFRSF10C reverse); 5'-

GAGTCAACGGATTTGGTCGT-3' (GAPDH forward), 5'-

TTGATTTTGGAGGGATCTCG-3' (GAPDH reverse). Real-time quantitative PCR was performed using the Applied Biosystems 7500 Real-Time PCR System with Power SYBR Green PCR master mix (Applied Biosystems). The PCR was terminated at the exponential phases: 50 cycles for TNFRSF10C and GAPDH, including 1 cycle of hot start at $95{ }^{\circ} \mathrm{C}$ for 10 minutes, followed by amplification at $95{ }^{\circ} \mathrm{C}$ for 15 seconds, $60^{\circ} \mathrm{C}$ for 32 seconds, and $72{ }^{\circ} \mathrm{C}$ for 30 seconds. Each reaction was performed in duplicate and negative controls were included in each experiment. The gene expression was quantified as the yield of the TNFRSF 10C relative to that of GAPDH. Control sample (DMSO) was employed as a calibrator and the $2^{-(\Delta \Delta \mathrm{CT})}$ formula was used as described [26]. 


\section{Statistical analysis}

Differences in the frequency of DNA methylation at TNFRSF10C promoter CGI between grades or deletion were tested using Fisher's exact test. Differences in TNFRSF10C gene expression between groups of tissues with different TNFRSF10C status (tumors with one copy of TNFRSF10C deleted and the other copy methylated, tumors with TNFRSF10C deletion but not methylation, tumors with TNFRSF10C methylation but not deletion, and normal tissues with intact TNFRSF10C) were tested by General Linear Model analysis. Differences in TNFRSF10C gene expression between groups of tumors with different TNFRSF10C status (tumors with one copy of TNFRSF10C deleted and the other copy methylated, tumors with TNFRSF 10C deletion but not methylation, tumors with TNFRSF10C methylation but not deletion) compared to baseline (normal tissues with intact TNFRSF10C) were tested using Dunnett's Multiple Comparison Test.

\section{RESULTS}

To explore the potential role of $\mathrm{CpG}$ island methylation in the transcriptional silencing of the TNFRSF10C gene, we checked the methylation status in 59 pairs of DNA samples isolated from fresh-frozen prostate cancer tissues and matched normal controls with bisulfite sequencing, which is the gold standard for mapping methylation across $\mathrm{CpG}$ sites. After subcloning of PCR product generated from bisulfite-treated DNA using a pCR4-TOPO vector, sequencing of each selected clone provided the precise methylation status for $13 \mathrm{CpG}$ sites in and near the TNFRSF10C promoter CGI (as seen in Figure 1, 12 CpG sites within CGI and an additional CpG site located outside the CGI). Among these $13 \mathrm{CpG}$ sites, six of them were also surveyed by another study [16]. Overall, 48 of the 59 primary prostate cancer samples $(81.4 \%)$ showed evidence of hypermethylation of the TNFRSF10C promoter CGI (Table 1).

Additionally, TNFRSF10C promoter CGI hypermethylation in two of the matched normal prostate controls ( 2 we only detected.3\%) (Table 1). The proportion of TNFRSF10C promoter CGI hypermethylation in normal prostate tissue is consistent with two other studies [16,29].

We then evaluated whether TNFRSF10C promoter CGI hypermethylation was associated with clinical/pathological features like Gleason score. As the data shown in table 2,

hypermethylation of the TNFRSF10C promoter CGI occurred equally frequently in both lowgrade (Gleason score $\leq 7$ ) and high-grade tumors (Gleason score $\geq 8)(81.1 \%$ vs. $81.0 \%$ ).

The deletion status of TNFRSF10C in 59 pairs of samples was reanalyzed using our previous Affymetrix $100 \mathrm{~K}$ and/or 500K SNP mapping array data [27,28]. We used the same criteria to define copy number changes and found that among 59 prostate cancer samples, 44 (74.5\%) showed hemizygous deletion of the TNFRSF10C locus. No homozygous deletions of the TNFRSF10C locus were detected. Similarly, no association between deletion and Gleason scores $(73.0 \%$ vs. $76.2 \%$ between Gleason score $\leq 7$ and Gleason score $\geq 8)$ was observed.

To test whether biallelic inactivation, with one allele deleted and the other allele inactivated by promoter CGI hypermethylation, occurred for TNFRSF10C, we compared the frequency of TNFRSF10C promoter CGI methylation between TNFRSF10C deleted and non-deleted groups. As shown in table 2, TNFRSF10C promoter CGI methylation was observed in $81.8 \%$ of TNFRSF 10C deleted tumors, compared to $80.0 \%$ in TNFRSF10C retained tumors. There was no obvious trend in the frequency of promoter CGI hypermethylation among tumors with TNFRSF10C deletion compared to tumors without TNFRSF10C deletion. Additionally, there is no significant difference in biallelic inactivation frequency of TNFRSF10C between low grade tumors and high grade tumors, although the total biallelic inactivation frequency is $61 \%$ (data not shown). Interestingly, the great majority of the tumors examined $(94.9 \%, 56$ out of 59) harbor either a hemizygous deletion or promoter CGI hypermethylation of TNFRSF10C. 
The three tumors without TNFRSF10C hemizygous deletion and promoter CGI hypermethylation are all low grade tumors.

We also analyzed TNFRSF10C promoter CGI methylation and deletion status in three prostate cancer cell lines (LNCaP, PC3 and DU145) using bisulfite sequencing of multiple subclones and by examination of previous Affymetrix 100K SNP array data. PC3 and LNCaP showed dense methylation of the TNFRSF10C promoter CGI and DU145 showed more heterogeneity in the TNFRSF10C promoter CGI methylation status, with low frequency of methylation in each CpG site (Figure 2A and 2B). Among these three prostate cancer cell lines, hemizygous deletion of the TNFRSF10C loci was only found in PC3 but not in the other two cell lines.

Transcriptional silencing of TNFRSF10C by promoter CGI hypermethylation has not been reported in PCa. To evaluate the effect of promoter CGI hypermethylation on TNFRSF10C expression, the $\mathrm{PC} 3$ prostate cancer cell line was treated with DNA methyltransferase inhibitor 5-aza-2'-deoxycytidine (decitabine). The methylation status of TNFRSF10C promoter CGI was analyzed using bislufite sequencing of multiple subclones. Bisulfite sequencing analysis of the TNFRSF10C promoter CGI in PC3 demonstrated that treatment of 5-aza-2'-

deoxycytidine resulted in demethylation in the TNFRSF10C promoter CGI (Figure 2C). Realtime PCR results demonstrated that partial demethylation of TNFRSF10C promoter CGI was accompanied by a 29.6 fold increase in the transcriptional expression of TNFRSF10C ( $S D=$ 1.06, Figure 2D). The data indicate that silencing of the TNFRSF10C gene was achieved through promoter methylation in this prostate cancer cell line.

To determine whether TNFRSF10C promoter CGI methylation and deletion affects gene expression, we performed real-time PCR to measure expression levels in a subset of tumor and normal samples for which RNA samples are also available. In total, there are 18 tumor samples (11 of them harboring both TNFRSF10C deletion and methylation, four of them harboring only TNFRSF10C deletion but not TNFRSF10C methylation, and the rest of the three tumors with TNFRSF10C methylation but not TNFRSF10C deletion). Differences in TNFRSF10C gene expression among these four groups were statistically significant $(\mathrm{p}=0.00012$, General Linear Model test). There were also statistically significant differences between baseline group (normal tissue) and the tumor group harboring both deletion and methylation (mean difference in $\triangle \mathrm{Ct}$ for $T N F R S F 10 C=2.17,95 \% \mathrm{CI}=1.21$ to 3.13, $\mathrm{p}<0.001$ ), and between baseline group (normal tissue) and the tumor group harboring only promoter methylation but not deletion (mean difference in $\triangle \mathrm{Ct}$ for $T N F R S F 10 C=1.42,95 \% \mathrm{CI}=0.023$ to 2.82, $\mathrm{p}=0.03$ ) (Figure 3).

\section{DISCUSSION}

We report here that hypermethylation of the TNFRSF10C gene promoter is found in a high proportion of primary sporadic prostate cancer. 48 of 59 tumors $(81.4 \%)$ were found to harbor TNFRSF 10C promoter CGI hypermethylaltion, which is higher than the previously reported frequencies in many other tumors including $\mathrm{PCa}$ (ranges from 16\% 63\%; 50\% for PCa) [16 18]. Additionally, the frequency of TNFRSF10C deletion found in this study (74.6\%) is also much higher than the average 8p21.3 deletion (34\%) [2]. Even more interesting, a great majority of the tumors examined (94.9\%) harbor either a TNFRSF10C hemizygous deletion or promoter CGI hypermethylation. Our study demonstrated a high prevalence of TNFRSF10C hemizygous deletion or promoter CGI hypermethylation in sporadic PCa.

In addition to the high prevalence of TNFRSF10C hemizygous deletion or promoter CGI hypermethylation observed in this study, our data also showed that both promoter hypermethylation and deletion contribute to a decrease in TNFRSF10C gene expression in prostate tumors, albeit tested in a small sample size. There was a dosage effect in term of TNFRSF 10C promoter hypermethylation or deletion on its gene expression. It was found that 
TNFRSF 10C gene expression levels were highest in normal prostate tissues, followed by tumors harboring either TNFRSF10C promoter hypermethylation or deletion, with the lowest expression levels seen in tumors harboring both TNFRSF10C promoter hypermethylation and deletion. Our results suggest that both TNFRSF 10C promoter hypermethylation and deletion contribute to TNFRSF10C gene silencing in prostate tumors. In addition, our in vitro experiment also demonstrated that partial demethylation of TNFRSF10C promoter CGI after treatment with the 5-aza-2'-deoxycytidine demethylation agent was accompanied by a 29.6 fold increase in transcriptional expression of TNFRSF10C in the PC 3 cell line. The results from examining clinical specimens and from in vitro cell line experiment suggested hypermethylation of TNFRSF10C promoter CGI is causal in TNFRSF10C gene suppression.

Several studies have correlated that TNFRSF10C promoter CGI hypermethylation was correlated with improved prognosis, while unmethylated TNFRSF 10C promoter CGI predicted a poorer disease-free survival rate $[17,29]$. However, we did not observe any correlation between hypermethylation of TNFRSF10C promoter CGI, hemizygous deletion of TNFRSF10C locus or biallelic inactivation of TNFRSF10C with Gleason grade ( $\leq 7 \mathrm{vs.} \geq 8$ ). This discrepancy could be due to the relatively small sample sizes of our study.

TNFRSF10C, the decoy receptor of TRAIL, lacks an intracellular death domain, and its extracellular domain is known to compete with those of the death receptors TNFRSF10A and TNFRSF $10 B$ for TNF-related apoptosis-inducing ligand (TRAIL) binding, resulting in the inhibition of apoptosis induction [30]. The exact mechanism of down-regulation of TNFRSF10C by methylation, deletion, or both in tumorigenesis is not clear. Currently, there are two potential mechanisms proposed for TNFRSF10C in cancer initiation and development. First, down-regulation of TNFRSF10C, therefore eliminating its anti-apoptosis effect, would represent a protective response against tumor progression. This could explain the results of improved prognosis in patients with hypermethylation of TNFRSF10C promoter CGI, and poorer survival rate in patients without hypermethylation of TNFRSF10C promoter CGI [17, 29]. However, this proposed mechanism is inconsistent with our and others' $[17,19]$ observations that down-regulation of TNFRSF10C is a very frequent event in tumors. The second proposed mechanism suggests the potential pro-apoptosis role of TNFRSF10C in tumors. In addition to its role in the induction of apoptosis, TRAIL receptors are also known to activate the NF- $\kappa B$ pathway [31,32]. The NF- $\mathrm{B}$ pathway is pro-apoptotic and has been implicated in the pathogenesis of many human malignancies [33]. It is likely that TRAIL, through TRAIL receptors, predominantly activates the NF- $\mathrm{KB}$ pathway instead of the apoptosis pathway in cancer cells, as opposed to their functions in normal cells [17]. If this is the case, the cancer cells gain advantage for proliferation and progression by inactivating TNFRSF10C through deletion and epigenetic modification of the promoter CGI. This potential mechanism is consistent with our and others' $[17,19]$ observations that down-regulation of TNFRSF10C is a very frequent event in tumors.

\section{CONCLUSIONS}

In summary, our results indicate that promoter CGI methylation and deletion of TNFRSF10C were commonly found in PCa tissues. Additionally, inactivation of TNFRSF 10C, indicated by the presence of chromosomal deletion and promoter CGI methylation in the same tumor tissue, may play an important role in PCa. However, the exact role of inactivation of TNFRSF 10C in cancer pathogenesis and development is still unclear. Further functional studies are warranted.

\section{Acknowledgments}

The authors thank all the study subjects who participated in this study. 
The authors thank AR Turner and TS Adams for editorial assistance.

This study is supported by National Cancer Institute CA95052 to J.X. and CA119069 to B.C.

\section{REFERENCES}

1. Nelson WG, De Marzo AM, Isaacs WB. Prostate cancer. N Engl J Med 2003;349(4):366-381. [PubMed: 12878745]

2. Sun J, Liu W, Adams TS, Sun J, Li X, Turner AR, Chang B, Kim JW, Zheng SL, Isaacs WB, Xu J. DNA copy number alterations in prostate cancers: a combined analysis of published CGH studies. Prostate 2007;67(7):692-700. [PubMed: 17342750]

3. Chang BL, Liu W, Sun J, Dimitrov L, Li T, Turner AR, Zheng SL, Isaacs WB, Xu J. Integration of somatic deletion analysis of prostate cancers and germline linkage analysis of prostate cancer families reveals two small consensus regions for prostate cancer genes at 8p. Cancer Res 2007;67(9):40984103. [PubMed: 17483320]

4. Banks RE, Tirukonda P, Taylor C, Hornigold N, Astuti D, Cohen D, Maher ER, Stanley AJ, Harnden P, Joyce A, Knowles M, Selby PJ. Genetic and epigenetic analysis of von Hippel-Lindau (VHL) gene alterations and relationship with clinical variables in sporadic renal cancer. Cancer Res 2006;66:20002011. [PubMed: 16488999]

5. Peng D, Ren CP, Yi HM, Zhou L, Yang XY, Li H, Yao KT. Genetic and epigenetic alterations of DLC-1, a candidate tumor suppressor gene, in nasopharyngeal carcinoma. Acta Biochim Biophys Sin 2006;38:349-355. [PubMed: 16680376]

6. Tokumaru Y, Nomoto S, Jeronimo C, Henrique R, Harden S, Trink B, Sidransky D. Biallelic inactivation of the RIZ1 gene in human gastric cancer. Oncogene 2003;22:6954-6958. [PubMed: 14534544]

7. Wei M, Grushko TA, Dignam J, Hagos F, Nanda R, Sveen L, Xu J, Fackenthal J, Tretiakova M, Das $\mathrm{S}$, Olopade OI. BRCA1 promoter methylation in sporadic breast cancer is associated with reduced BRCA1 copy number and chromosome 17 aneusomy. Cancer Res 2005;65:10692-10699. [PubMed: 16322213]

8. Yi HM, Li H, Peng D, Zhang HJ, Wang L, Zhao M, Yao KT, Ren CP. Genetic and epigenetic alterations of LTF at 3p21.3 in nasopharyngeal carcinoma. Oncol Res 2006;16:261-272. [PubMed: 17476971]

9. Takada H, Imoto I, Tsuda H, Nakanishi Y, Sakakura C, Mitsufuji S, Hirohashi S, Inazawa J. Genomic loss and epigenetic silencing of very-low-density lipoprotein receptor involved in gastric carcinogenesis. Oncogene 2006;25:6554-6562. [PubMed: 16715143]

10. Chughtai SA, Crundwell MC, Cruickshank NR, Affie E, Armstrong S, Knowles MA, Takle LA, Kuo M, Khan N, Phillips SM, Neoptolemos JP, Morton DG. Two novel regions of interstitial deletion on chromosome 8p in colorectal cancer. Oncogene 1999;18(3):657-665. [PubMed: 9989816]

11. Wistuba II, Behrens C, Virmani AK, Milchgrub S, Syed S, Lam S, Mackay B, Minna JD, Gazdar AF. Allelic losses at chromosome 8p21-23 are early and frequent events in the pathogenesis of lung cancer. Cancer Res 1999;59(8):1973-1979. [PubMed: 10213509]

12. Chain H, MacDonald JW, Vessella RL, Washburn JG, Quinn JE, Odman A, Rubin MA, Macoska JA. Haploinsufficiency and reduced expression of genes localized to the $8 \mathrm{p}$ chromosomal region in human prostate tumors. Genes Chromosomes Cancer 2003;37(3):306-313. [PubMed: 12759929]

13. Charafe-Jauffret E, Moulin JF, Ginestier C, Bechlian D, Conte N, Geneix J, Adélaïde J, Noguchi T, Hassoun J, Jacquemier J, Birnbaum D. Loss of heterozygosity at microsatellite markers from region p11-21 of chromosome 8 in microdissected breast tumor but not in peritumoral cells. Int J Oncol 2002;21(5):989-996. [PubMed: 12370745]

14. Adams J, Williams SV, Aveyard JS, Knowles MA. Loss of heterozygosity analysis and DNA copy number measurement on $8 \mathrm{p}$ in bladder cancer reveals two mechanisms of allelic loss. Cancer Res 2005 Jan 1;65(1):66-75. [PubMed: 15665280]

15. Ono K, Miyakawa A, Fukuda M, Shiiba M, Uzawa K, Watanabe T, Miya T, Yokoe H, Imai Y, Tanzawa H. Allelic loss on the short arm of chromosome 8 in oral squamous cell carcinoma. Oncol Rep 1999 Jul-Aug;6(4):785-759. [PubMed: 10373657]

16. Van Noesel MM, van Bezouw S, Salomons GS, Voûte PA, Pieters R, Baylin SB, Herman JG, Versteeg R. Tumor-specific down-regulation of the tumor necrosis factor-related apoptosis-inducing ligand 
decoy receptors DcR1 and DcR2 is associated with dense promoter hypermethylation. Cancer Res 2002;62(7):2157-2161. [PubMed: 11929838]

17. Shivapurkar N, Toyooka S, Toyooka KO, Reddy J, Miyajima K, Suzuki M, Shigematsu H, Takahashi T, Parikh G, Pass HI, Chaudhary PM, Gazdar AF. Aberrant methylation of trail decoy receptor genes is frequent in multiple tumor types. Int J Cancer 2004;109(5):786-792. [PubMed: 14999791]

18. Michalowski MB, de Fraipont F, Michelland S, Entz-Werle N, Grill J, Pasquier B, Favrot MC, Plantaz D. Methylation of RASSF1A and TRAIL pathway-related genes is frequent in childhood intracranial ependymomas and benign choroid plexus papilloma. Cancer Genet Cytogenet 2006;166(1):74-81. [PubMed: 16616114]

19. Hornstein M, Hoffmann MJ, Alexa A, Yamanaka M, Müller M, Jung V, Rahnenführer J, Schulz WA. Protein Phosphatase and TRAIL Receptor Genes as New Candidate Tumor Genes on Chromosome $8 p$ in Prostate Cancer. Cancer Genomics Proteomics 5(2):123-136. [PubMed: 18460741]

20. Bova GS, Carter BS, Bussemakers MJ, Emi M, Fujiwara Y, Kyprianou N, Jacobs SC, Robinson JC, Epstein JI, Walsh PC. Homozygous deletion and frequent allelic loss of chromosome 8p22 loci in human prostate cancer. Cancer Res 1993;53:3869-3873. [PubMed: 7689419]

21. Warnecke PM, Stirzaker C, Song J, Grunau C, Melki JR, Clark SJ. Identification and resolution of artifacts in bisulfite sequencing. Methods 2002;27(2):101-107. [PubMed: 12095266]

22. Dunn T, Chen S, Faith D, Hicks J, Platz E, Chen Y, Ewing C, Sauvageot J, Isaacs W, De Marzo A, Luo J. A Novel Role of Myosin VI in Human Prostate Cancer. American Journal of Pathology 2006;169(5):1843-1854. [PubMed: 17071605]

23. Personal communication with Dr. Jun Luo, Johns Hopkins University.

24. Wong ML, Medrano JF. Real-time PCR for mRNA quantitation. Biotechniques 2005;39(1):75-85. [PubMed: 16060372]

25. Sanlioglu AD, Dirice E, Aydin C, Erin N, Koksoy S, Sanlioglu S. Surface TRAIL decoy receptor-4 expression is correlated with TRAIL resistance in MCF7 breast cancer cells. BMC Cancer 2005;5 (1):54. [PubMed: 15916713]

26. Livak KJ, Schmittgen TD. Analysis of relative gene expression data using real-time quantitative PCR and the 2(-Delta Delta C(T)) Method. Methods 2001;25:402-408. [PubMed: 11846609]

27. Liu W, Chang B, Sauvageot J, Dimitrov L, Gielzak M, Li T, Yan G, Sun J, Sun J, Adams TS, Turner AR, Kim JW, et al. Comprehensive assessment of DNA copy number alterations in human prostate cancers using Affymetrix 100K SNP mapping array. Genes Chromosomes Cancer 2006;45:10181032. [PubMed: 16897747]

28. Liu W, Chang BL, Cramer S, Koty PP, Li T, Sun J, Turner AR, Kap-Herr C, Bobby P, Rao J, Zheng $\mathrm{SL}$, Isaacs WB, et al. Deletion of a small consensus region at $6 \mathrm{q} 15$, including the MAP3K7 gene, is significantly associated with high-grade prostate cancers. Clin Cancer Res 2007;13:5028-5033. [PubMed: 17785553]

29. Suzuki M, Shigematsu H, Shivapurkar N, Reddy J, Miyajima K, Takahashi T, Gazdar AF, Frenkel EP. Methylation of apoptosis related genes in the pathogenesis and prognosis of prostate cancer. Cancer Lett 2006;242(2):222-230. [PubMed: 16458425]

30. Murphy TM, Perry AS, Lawler M. The emergence of DNA methylation as a key modulator of aberrant cell death in prostate cancer. Endocr Relat Cancer 2008;15(1):11-25. [PubMed: 18310272]

31. Chaudhary PM, Eby M, Jasmin A, Bookwalter A, Murray J, Hood L. Death receptor 5, a new member of the TNFR family, and DR4 induce FADD-dependent apoptosis and activate the NF-B pathway. Immunity 1997;7:821-830. [PubMed: 9430227]

32. Schneider P, Thome M, Burns K, Bodmer JL, Hofmann K, Kataoka T, Holler N, Tschopp J. TRAIL receptors 1 (DR4) and 2 (DR5) signal FADD-dependent apoptosis and activate NF-B. Immunity 1997;7:831-836. [PubMed: 9430228]

33. Gilmore TD, Koedood M, Piffat KA, White DW. Rel/NF-B/IB proteins and cancer. Oncogene 1996;13:1367-1378. [PubMed: 8875974] 


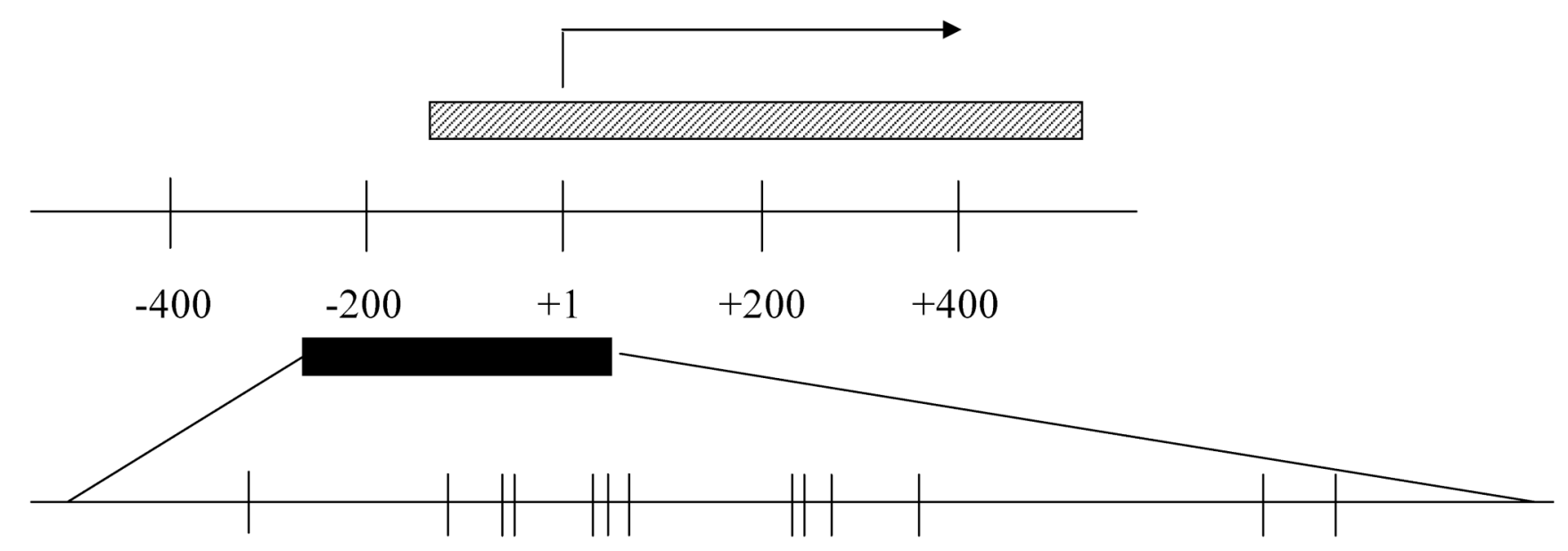

Figure 1.

Schematic representation of TNFRSF10C promoter region. The TNFRSF10C transcription start site is marked with $\mathrm{a}+1$ and an arrow. Amplicon $(-257 \sim+30)$ for sequencing and $\mathrm{CpG}$ island $(-130 \sim+413)$ are indicated by filled and stripped bars, respectively. Vertical lines in a sequencing amplicon are indicated $\mathrm{CpG}$ sites. 
$\mathbf{A}$

\begin{tabular}{|c|c|c|c|}
\hline \multirow{2}{*}{ Cell Line } & \multirow{2}{*}{$\begin{array}{c}\text { TNFRSF10 } \\
\text { hemideletion }\end{array}$} & $\begin{array}{c}|c| \\
\text { Mumber of } \\
\text { Methylated } \\
\text { clone }\end{array}$ & $\begin{array}{c}\text { Total number } \\
\text { of clone }\end{array}$ \\
\hline PC3 & Yes & 10 & 10 \\
\hline LNCaP & No & 6 & 6 \\
\hline DU145 & No & 1 & 12 \\
\hline
\end{tabular}

C

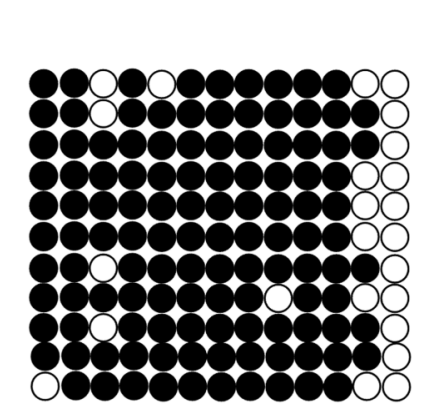

PC3

+DMSO

PC3

+Aza-dC
B

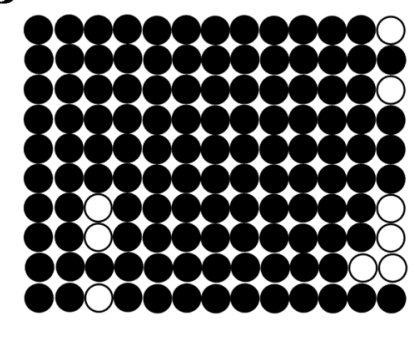

PC3

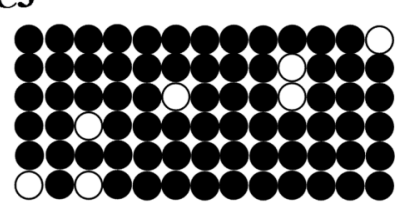

LNCaP

D

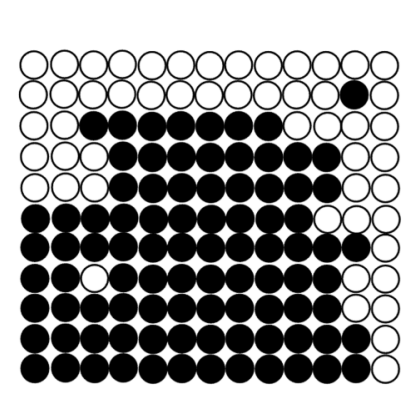

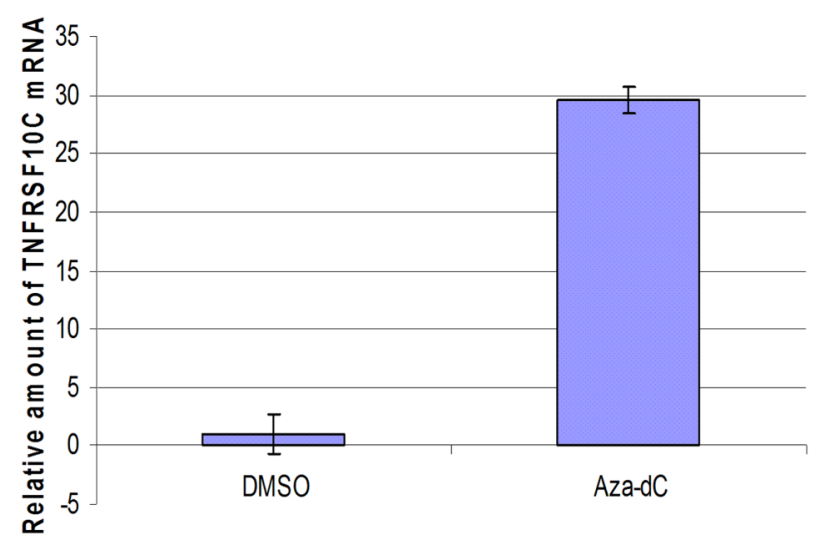

Figure 2.

Reduction of TNFRSF10C hypermethylation and reactivation of TNFRSF10C expression in prostate cancer cells in vitro by treatment with a demethylating agent. A. Methylation status of TNFRSF 10C in 3 prostate cancer cell lines was analyzed by bisulfite sequencing. B. Bisulfite sequencing of TNFRSF10C CGI in three prostate cancer cell lines PC3, DU145 and LNCaP. Each row represents one bacterial clone with one circle symbolizing one $\mathrm{CpG}$ site. $\mathrm{C}$. Bisulfite sequencing of TNFRSF10C CGI after treatment with a demethylation agent (Aza-dC) or DMSO (as a control). D. Analysis of TNFRSF 10C mRNA expression by quantitative RT-PCR after treatment with a demethylation agent. 


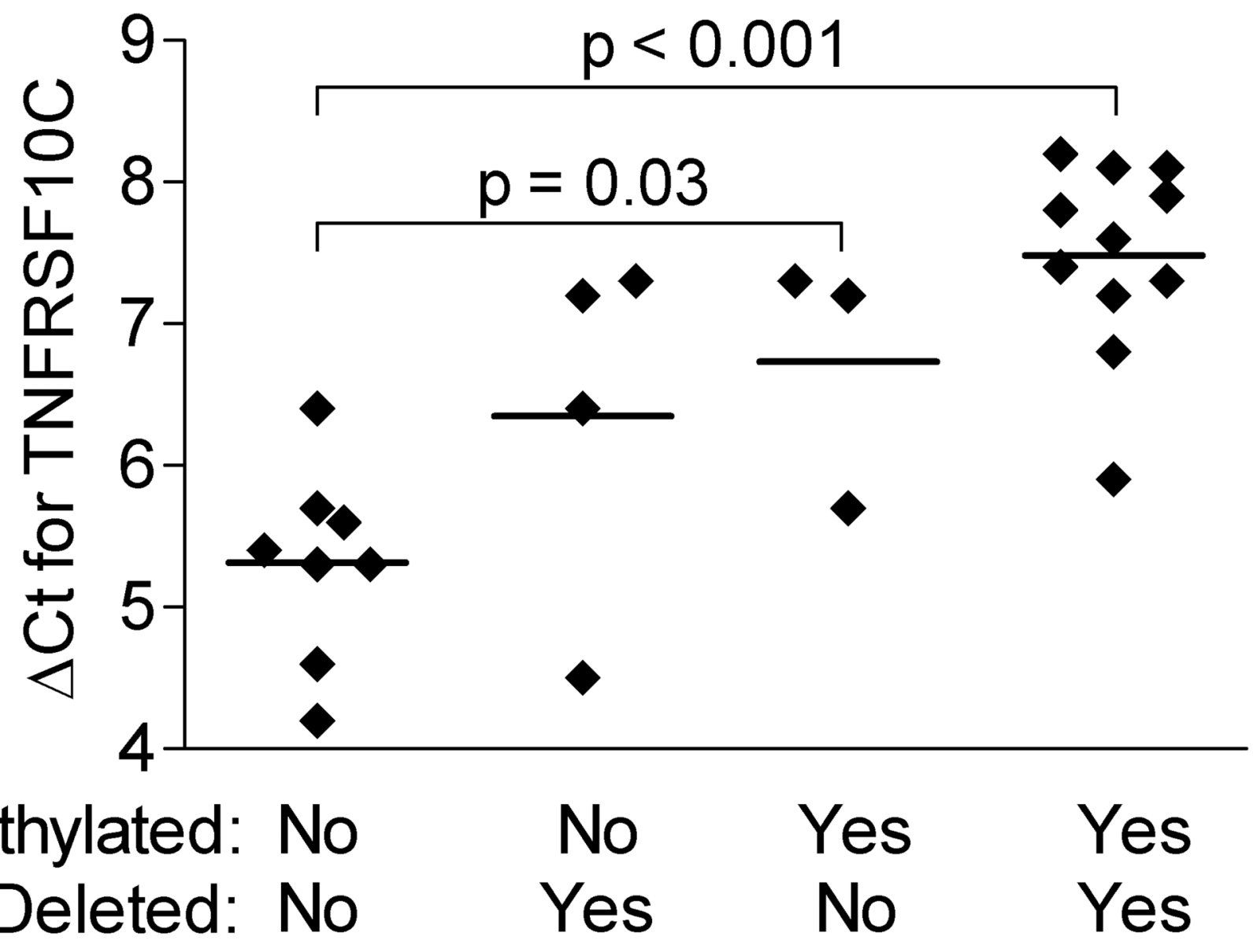

Figure 3.

Correlation of TNFRSF10C hypermethylation and deletion with TNFRSF10C gene expression in prostate tumors and normal tissues. The y-axis indicates $\triangle \mathrm{Ct}$ of TNFRSF10C. The $\mathrm{x}$-axis indicates four groups of tissues in comparison: 1) normal tissues with no methylation and deletion at TNFRSF10C, 2) tumors with TNFRSF10C promoter hypermethylation but not deletion, 3) tumors with one copy of TNFRSF10C deleted but no promoter hypermethylation, and 4) tumors with one copy of TNFRSF10C deleted and the other copy methylated. 
Table 1

Methylation and deletion status of TNFRSF10C in primary prostate cancer samples.

\begin{tabular}{|c|c|c|c|c|}
\hline \multirow{2}{*}{ Sample ID } & \multirow{2}{*}{ Gleason score } & \multirow{2}{*}{$\begin{array}{c}\text { TNFRSF10C } \\
\text { hemizygous } \\
\text { deletion }\end{array}$} & \multicolumn{2}{|c|}{ Methylation } \\
\hline & & & Tumor & Normal \\
\hline G6-002 & 6 & Yes & $\mathrm{U}$ & $\mathrm{U}$ \\
\hline G6-003 & 6 & No & M & $\mathrm{U}$ \\
\hline G6-013 & 6 & Yes & M & $\mathrm{U}$ \\
\hline G6-015 & 6 & Yes & M & $\mathrm{U}$ \\
\hline G6-016 & 6 & Yes & M & $\mathrm{U}$ \\
\hline G6-017 & 6 & No & M & $\mathrm{U}$ \\
\hline G6-018 & 6 & No & M & $\mathrm{U}$ \\
\hline G6-019 & 6 & Yes & M & $\mathrm{U}$ \\
\hline G6-020 & 6 & No & $\mathrm{U}$ & $\mathrm{U}$ \\
\hline G7-002 & 7 & Yes & M & $\mathrm{U}$ \\
\hline G7-013 & 7 & Yes & M & $\mathrm{U}$ \\
\hline G7-015 & 7 & Yes & M & $\mathrm{U}$ \\
\hline G7-016 & 7 & Yes & $\mathrm{U}$ & $\mathrm{U}$ \\
\hline G7-017 & 7 & Yes & M & $\mathrm{U}$ \\
\hline G7-018 & 7 & No & M & $\mathrm{U}$ \\
\hline G7-019 & 7 & Yes & M & M \\
\hline G7-020 & 7 & Yes & M & $\mathrm{U}$ \\
\hline G7-021 & 7 & Yes & M & $\mathrm{U}$ \\
\hline G7-022 & 7 & Yes & M & $\mathrm{U}$ \\
\hline G7-023 & 7 & Yes & M & $\mathrm{U}$ \\
\hline G7-026 & 7 & Yes & $\mathrm{U}$ & $\mathrm{U}$ \\
\hline G7-028 & 7 & Yes & M & $\mathrm{U}$ \\
\hline G7-029 & 7 & Yes & M & $\mathrm{U}$ \\
\hline G7-030 & 7 & Yes & M & $\mathrm{U}$ \\
\hline G7-032 & 7 & No & $\mathrm{U}$ & $\mathrm{U}$ \\
\hline G7-033 & 7 & Yes & M & $\mathrm{U}$ \\
\hline G7-042 & 7 & Yes & M & $\mathrm{U}$ \\
\hline G7-048 & 7 & No & M & $\mathrm{U}$ \\
\hline G7-049 & 7 & No & M & $\mathrm{U}$ \\
\hline G7-050 & 7 & Yes & M & $\mathrm{U}$ \\
\hline G7-051 & 7 & Yes & M & $\mathrm{U}$ \\
\hline G7-052 & 7 & Yes & M & $\mathrm{U}$ \\
\hline G7-054 & 7 & No & M & $\mathrm{U}$ \\
\hline G7-055 & 7 & No & $\mathrm{U}$ & $\mathrm{U}$ \\
\hline G7-056 & 7 & Yes & M & $\mathrm{U}$ \\
\hline G7-057 & 7 & Yes & M & $\mathrm{U}$ \\
\hline
\end{tabular}




\begin{tabular}{|c|c|c|c|c|}
\hline \multirow{2}{*}{ Sample ID } & \multirow{2}{*}{ Gleason score } & \multirow{2}{*}{$\begin{array}{c}\text { TNFRSF10C } \\
\text { hemizygous } \\
\text { deletion }\end{array}$} & \multicolumn{2}{|c|}{ Methylation } \\
\hline & & & Tumor & Normal \\
\hline G7-058 & 7 & Yes & $\mathrm{U}$ & $\mathrm{U}$ \\
\hline G8-002 & 8 & Yes & M & $\mathrm{U}$ \\
\hline G8-003 & 8 & No & M & $\mathrm{U}$ \\
\hline G8-004 & 8 & Yes & M & $\mathrm{U}$ \\
\hline G8-012 & 8 & Yes & $\mathrm{M}$ & $\mathrm{U}$ \\
\hline G8-013 & 8 & Yes & M & $\mathrm{U}$ \\
\hline G9-001 & 9 & Yes & M & M \\
\hline G9-002 & 9 & No & $\mathrm{M}$ & $\mathrm{U}$ \\
\hline G9-003 & 9 & Yes & M & $\mathrm{U}$ \\
\hline G9-004 & 9 & Yes & $\mathrm{U}$ & $\mathrm{U}$ \\
\hline G9-005 & 9 & Yes & $\mathrm{M}$ & $\mathrm{U}$ \\
\hline G9-007 & 9 & No & M & $\mathrm{U}$ \\
\hline G9-008 & 9 & Yes & M & $\mathrm{U}$ \\
\hline G9-009 & 9 & Yes & M & $\mathrm{U}$ \\
\hline G9-010 & 9 & Yes & M & $\mathrm{U}$ \\
\hline G9-011 & 9 & Yes & $\mathrm{U}$ & $\mathrm{U}$ \\
\hline G9-012 & 9 & Yes & M & $\mathrm{U}$ \\
\hline G9-013 & 9 & Yes & $\mathrm{U}$ & $\mathrm{U}$ \\
\hline G9-014 & 9 & Yes & $\mathrm{U}$ & $\mathrm{U}$ \\
\hline G9-015 & 9 & Yes & M & $\mathrm{U}$ \\
\hline G10-001 & 10 & No & M & $\mathrm{U}$ \\
\hline G10-002 & 10 & No & $\mathrm{M}$ & $\mathrm{U}$ \\
\hline GN-001 & NI & Yes & M & $\mathrm{U}$ \\
\hline
\end{tabular}

M: Methylated TNFRSF10C, U: Unmethylated TNFRSF10C, NI: No information 
Table 2

Clinical characteristics of prostate cancer samples with TNFRSF10C methylation and deletion.

\begin{tabular}{|c|c|c|c|c|}
\hline \multirow{2}{*}{$\begin{array}{c}\text { TNFRSF10C } \\
\text { methylation } \\
(\%)\end{array}$} & \multirow{2}{*}{$\begin{array}{c}\text { TNFRSF10C } \\
\text { deletion }(\%)\end{array}$} & \multicolumn{3}{|c|}{ Gleason Score } \\
\cline { 3 - 5 } & & $30(81)$ & $17(81)$ & $48(81)$ \\
\hline+ & & $7(19)$ & $4(19)$ & $11(19)$ \\
\hline- & + & $27(73)$ & $16(76)$ & $44(75)$ \\
\hline & - & $10(27)$ & $5(24)$ & $15(25)$ \\
\hline & - & $3(8)$ & $0(0)$ & $3(5)$ \\
\hline+ & - & $7(19)$ & $5(24)$ & $12(20)$ \\
\hline+ & + & $4(11)$ & $4(19)$ & $8(14)$ \\
\hline- & + & $23(62)$ & $12(57)$ & $36(61)$ \\
\hline+ & & &
\end{tabular}

